\title{
Evaluation of Traffic Accessibility Condition and Noise Pollution in Dhaka City of Bangladesh
}

\author{
Zahidul Islam $^{1}$, Faruque Abdullah ${ }^{2, ~ *, ~ M a h m u d a ~ K h a n o m ~}{ }^{3}$ \\ ${ }^{1}$ Department of Civil Engineering, Rajshahi University of Engineering \& Technology, Rajshahi, Bangladesh \\ ${ }^{2}$ Department of Building Engineering and Construction Management, Rajshahi University of Engineering \& Technology, Rajshahi, \\ Bangladesh \\ ${ }^{3}$ Department of Civil Engineering, Rajshahi Science \& Technology University, Natore, Bangladesh
}

Email address:

zahid@ce.ruet.ac.bd (Z. Islam), abdullah@becm.ruet.ac.bd (F. Abdullah), mahmuda.ce.ruet@gmail.com (M. Khanom)

${ }^{*}$ Corresponding author

\section{To cite this article:}

Zahidul Islam, Faruque Abdullah, Mahmuda Khanom. Evaluation of Traffic Accessibility Condition and Noise Pollution in Dhaka City of Bangladesh. American Journal of Traffic and Transportation Engineering. Vol. 6, No. 2, 2021, pp. 43-51. doi: 10.11648/j.ajtte.20210602.12

Received: May 6, 2021; Accepted: May 24, 2021; Published: May 31, 2021

\begin{abstract}
Sound pollution and traffic jam are two major problems in most of the city roads of developing cities like as Dhaka, Bangladesh. Traffic jam, as well as mixed traffic condition, is the major cause of sound pollution in the city roads. Both of these issues affect mostly on country's public health and development. A lot of new roads have been constructed in Dhaka city every year but the majority of the roads have not been constructed considering the future AADT (Annual Average Daily Traffic) value. The traffic volume has increased a lot as the population of the country increased rapidly and shifting the status of the country from developing county to the developed country increased the demand for privet car and as a result traffic jam is a regular problem in the Dhaka city. Due to increasing traffic volume, the waiting time in the traffic jam has been increased consequently. Drivers bell the horn of their vehicle to attract the concentration of the traffic police so that the traffic police provide the green signal to his/her desired destination road. Also after the starting of the green signal or when the yellow signal is provided to the drivers, the driver bell horn of their vehicle so that low-speed vehicle side to high-speed vehicle. Besides these, bikers continuously press the hydraulic horn to provide them free access throughout their road. In this research work, we have attempted to show how much free access is available to Natun Bazar to Farmgate road, a major traffic-congested road in Dhaka city for both directions of traffic movement and also the present sound pollution condition in this road. On an average of $9.06 \%$ and $8.46 \%$ of a day the driver gets free access [green signal] on this route based on the traffic movement direction [Natun Bazar to Farmgate route]. At present on average it requires around $2 \mathrm{hr}$. for traveling $7 \mathrm{~km}$ road and this is a hotspot of huge time killing for the city people in their regular life. Besides this passenger has to bear a sound level of around $101 \mathrm{~dB}$ including the residents living in this area beside the roadway. This impact is tremendous for the bikers and bus passengers result, they are experiencing significant issues such as headaches, decreased job performance, decreased focus, exhaustion, tension, and tiredness.
\end{abstract}

Keywords: Traffic Jam, Congestion, Sound Pollution, Traffic Volume, Air Pollution

\section{Introduction}

The transportation system plays a significant role in a country's rapid growth. During this age of globalization, many structural elements have been developed on both sides of the major roads in Bangladesh without planning and considerations for the future development of the country. The city of Dhaka, Bangladesh's capital, is the epicenter of this practice. So the city dwellers are facing tremendous traffic jam problem nowadays in their daily life. Most of the city of Bangladesh is facing this traffic jam problem and it is a warning to the authority. [1] Besides this, the authority allows mixed traffic on the roads and most of the drivers don't follow traffic rules as well as many of them don't have a traffic license. According to reports from the Bangladesh Road Transport Authority (BRTA), Bangladesh had over 2.9 million licensed vehicles in February 2017, but only 65 
percent of them had a driving license. These "ghost" riders, who have no experience of traffic laws or responsible driving practices, have wreaked havoc on the highways. According to a passenger safety forum hosted by Bangladesh Jatri Kalyan Samity, at least 224 people were killed and 866 hurt in 203 road traffic accidents during the first 12 days of August 2019. [2] They are highly responsible for traffic jams as they frequently change their path on the road. Hence when a highspeed vehicle wants to go fast to arrive at the destination in the shortest time he presses the horn so that he might catch the concentration of the slow-moving vehicle's driver to provide him a clear pathway. High traffic congestion is undeniably a major hindrance and drawback, especially in urban agglomerations. External losses associated with lost time are greatly increased by traffic congestion. [3] Congestion is caused by poor traffic control and the objective to increase capability. [4-5] Drivers in Dhaka city tends to block the road and searching passenger for extra income but they don't provide free access to privet car also. When his demand is fulfilled in the present stoppage he tries to run the vehicle faster to reach the next stoppage earlier to do the same. As there are no strict rules for doing so they continue this kind of behavior day after day. In some stoppage, they unnecessarily stopped their vehicle and wait for the passenger to fill all the seats. Mainly this type of habit is seen to perform on crowded stoppage like as Farmgate. It's also a major factor in waste dispersion and the rate of pollution. [69] As the driver run their vehicle for a longer period, they produce huge waste and release in the environment. Congestion raises automobile pollution and degrades ambient air quality, and scientific investigations have shown a change in incidence and death for pedestrians, commuters, and people who live near major highways. Air Quality Index (AQI) value is going to worsen day by day due to improper driving performance. In addition, traffic flow conditions interrupted on the vehicular road causes disturbances on personal work performance. [10] Traffic noise is responsible for the intensive and spreading type of noise. [11]

Residents living along arterial roads in Allahabad city tolerate traffic noise better than those living along collector roads, with $57.5 \mathrm{~dB}$ and $56.2 \mathrm{~dB}$, respectively, during the day. For circulatory and collector roads, it is $2.5 \mathrm{~dB}$ and $1.2 \mathrm{~dB}$ respectively which is more than the prescribed level of $55 \mathrm{~dB}$ as guided by the Ministry of Environment and Forests (MoEF). Residents' estimated acceptability level of road noise at night is 46.0 decibels, which is 1 decibel greater than MoEF and WHO nighttime traffic noise limits of 45 de, cables WHO. [12] For Dhaka city this value is quite more as roads are very narrow and traffic jam is a common phenomenon in regular lifestyle of city people. Although for residential area day time highest noise level standard is $50 \mathrm{~dB}$ but still now no steps have been taking from the authority on this problem. Road noise has also been reported as a global public health issue by the World Health Organization. [13] The number of impulsive noise (noise that lasts for a brief period) has risen by $10 \%$ to $12 \%$. According to a survey performed in November and December last year, persistent noise (noise that persists for a longer period of time) decreased by 3-4 percent compared to 2019 . In comparison, relative to 2019 , the report observed $15 \%$ less traffic on the city's highways due to Corona Pandemic Situation in Bangladesh. According to a report conducted by Stamford University's Centre for Atmospheric Pollution Studies (CAPS), the use of banned hydraulic horns has increased by 15-25 percent on city roads. Horns are responsible for a large majority of the city's impulsive noise. Anyone who is subjected to even more than $100 \mathrm{~dB}$ sound for more than 15 minutes can experience temporary deafness. A sound of 120 decibels can cause permanent hearing loss. [14] About 210 million residents in road-noise subject to several noises, which has a number of negative health effects. Disturbance of sleep, movements, efficiency, and attention, discomfort and stress, biological risk factors, cardiovascular conditions, and psychological disorders are all examples of noiseinduced health effects. [15] The effect of noise on urban citizens' lives has been investigated intensively. [6, 16 - 17] It is harmful to one's welfare. Stress and arterial pressure both rise due to a long period of travel time. As a result, the driver's ability to react appropriately deteriorates, and safety suffer as well. [18-19] The auditory and nervous systems of urban residents, especially children, can be severely stressed by high noise levels. Severe symptoms, such as deafness and mental collapse, have been recorded on occasion. [20] In Europe, the social costs of road noise above $55 \mathrm{~dB}$ in 2007 were estimated to be at least 38 (30-46) billion euros. Noiserelated social expenses for rail travel are estimated to be about 2.4 (2.3-2.5) billion euros a year. These estimates are most probably an underestimation of the real costs. [15] Road noise not only has negative health impacts, but it also lowers land prices. Highway pollution in the United States lowered residential property prices by $\$ 6-182 / \mathrm{dB}$ even after elimination. [21] The study mainly focuses on the accessibility of vehicles on road and their impact on a human being.

\section{Review of Existing Literature}

Hui et al. (2018) evaluated the quality of a metropolitan environmental situation adequately by using noise pollution measurement methods. They were able to predict the region's actual sound levels and energy quality standards using these methods. After conducting several assessments of various road categories for every ten minutes in several urban areas in Chang Chung district, they assessed eight samples of analogous sound levels. Their traffic noise amplification method was able to predict the instantaneous noise levels with a small margin of error. When people were used to a poor environmental situation for a long period, it had a significant impact on their normal lives. [22]

In 2016, Sonjoy Chakraborty discussed the detrimental effects of traffic congestion on Bangladesh's economy. Based on five expense computation [travel delay externality cost, dead-weight reduction loss, travel time expense, real-time air pollution \& vehicle running cost], the study exhibit that 
mitigating traffic jam only in Dhaka city can increase the Gross Domestic Product (GDP) of Bangladesh to 35\% and as a result, it will make a great positive impact on the national economy as well as on the environment. [23]

Daljeet Singh et al. (2016) provided the green light for a creative strategy to forecast vehicular traffic noise using machine learning algorithms. On an hourly basis, they were able to predict the corresponding continuous sound pressure levels in Patiala City. They used the mean velocity of the vehicle, the number of heavy cars, and traffic volume as input constraints variables for this reason. Aside from that, the accomplishments of the Standard Model Structure, Decision Trees, Random Forests, and Genetic Algorithms were reliably calculated using several metrics. As a result, they were able to determine that the Random Forests outperformed the parallel strategies in terms of sound intensity estimation. [24]

Rao \& Rao (2012) introduce a novel and fascinating technique for identifying traffic congestion on India's urban arterials, as well as alternative methods for identifying and measuring metrics for urban arterial congestion. A comprehensive analysis is conducted based on the traffic control parameters like speed, travel time/delay, and volume of traffic. They recommend using a Wi-Fi signal transmitting network and a detector across the street to detect the congestion. This method was found to be effective in deciding whether a route is crowded or free-flowing with great accuracy. [25]

A closer inspection of the literary works listed above reveals that, despite the attempts of many scientists to simulate traffic noise, monitor and track traffic congestion, no fruitful outcomes appear to have been obtained for detecting and tracking traffic congestion. However, several researchers used a Wi-Fi transmitting network and manually for detecting traffic congestion on street. Monitoring traffic congestion for the whole day is so complex for a person and there is a chance of error as well as for Wi-Fi transmitting network as there is a chance of missing data due to network error or faulty in the devices. On the other hand, Google Maps may be the suitable option for traffic congestion monitoring as it is operated by satellite (GPS technology). The approach proposes a new strategy for traffic noise estimation to overcome the relative challenges.

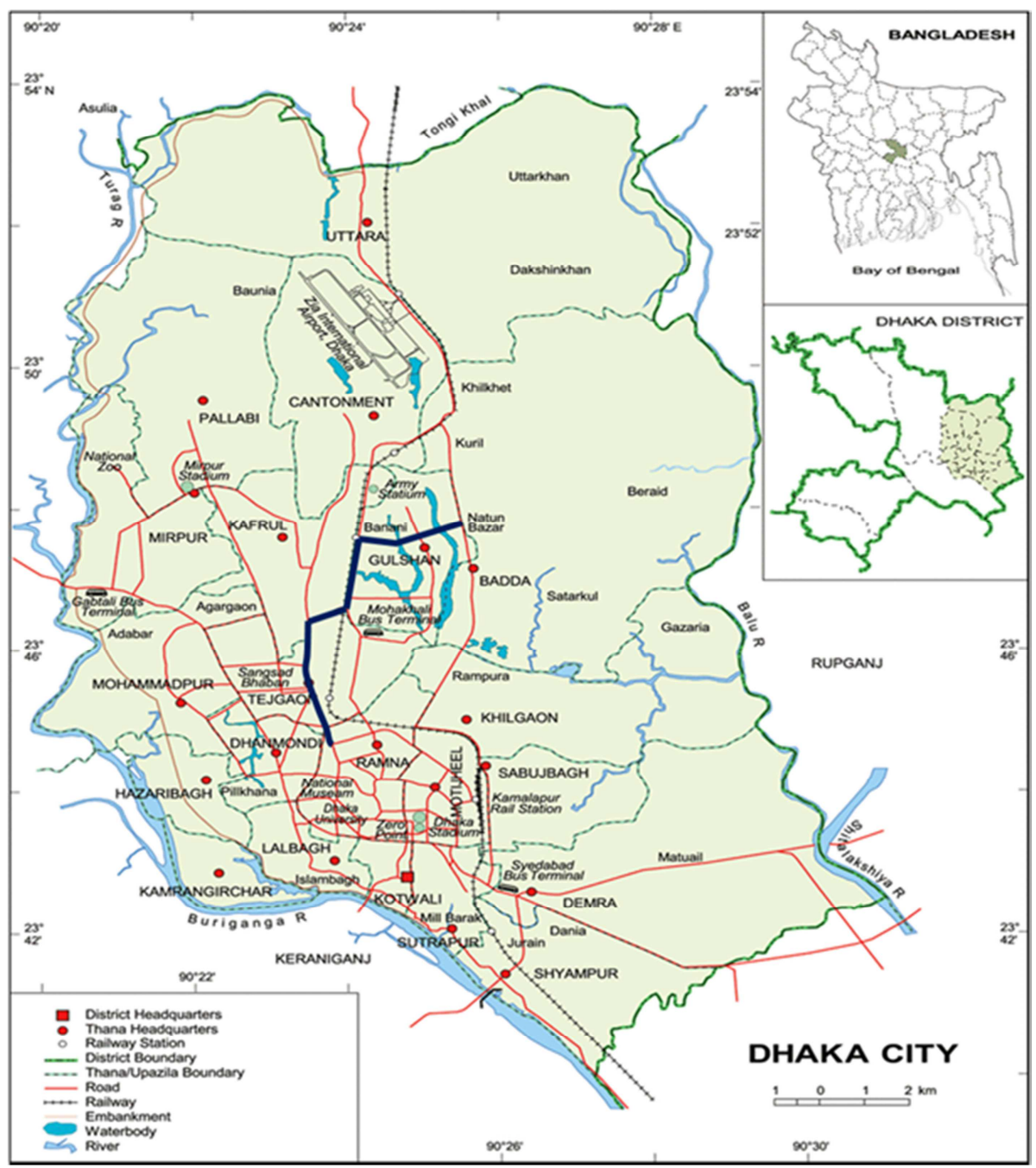

Figure 1. Selected route on Dhaka city map. 


\section{Materials \& Methodology}

The human ear seems to have a dynamic response to sound. The physical calculation of sound intensity level and an individual's understanding of the loudness of sounds do not have a clear relationship. The human ear does not react to all wavelengths, even though the sound is made up of them. Wavelengths that the auditory system would not respond should be screened out when evaluating highway sound quality. [26] Weighting loops, which strip out specific frequencies, are commonly used in sound-level meters. The A-scale on a noise level sensor more likely represents the sound quality of the human ear. [27]. Sound amplitude and pressure are the most popular indicators of sound level. The effective amount of noise energy released per unit surface area perpendicular to the acoustic wave path, expressed in Pico-waits per square meter, is known as sound intensity. [28]. As no instrument might be used to take a direct measure in this field. The square of sound force is normally equal to sound intensity. [29] Sound frequency is represented using a logarithmic scale known as decibel $(\mathrm{dB})$ and it deals with a wide variety of numbers. Several types of vehicles, such as heavy and light trucks/buses, motorcycles, and two-wheelers, are likely to be the source of street noise. The total noise is influenced by a variety of aspects, such as the vehicle movement and the proportions of various transportation modes in the road network. [30]

\subsection{Scope and Area of the Study}

In Bangladesh, 'Farmgate' is the key connection point to travel all the major regions of Dhaka city. Among all the city routes the Natun Bazar to Farmgate route is the most densely vehicular route and source of huge noise pollution which can clearly be understood from figure 1. [31] This route is also important based on the economic background of the city. The most significant aspect of this route is both side of the link road [Natun Bazar to Banani] is connected with the International Airport of the city.

\subsection{Data Collection}

Taking the investigation's overall objective into mind, a field information collection plan is meant to accurately collect the necessary data for the assessment's noise level. Based on the survey, several spots of highway road [Natun Bazar to Farmgate] have been shortlisted due to heavy traffic concerns. The chosen position in our case study is near the bus stations, where traffic congestion is a frequent occurrence. These spots are Natun Bazar, Gulshan-2, Banani, Shoinik Club Mor, Mohakhali Fly-over, Jahangir Gate, Bijoy Sarani \& Farmgate. The illegal movement of two-wheelers and auto-rickshaws is primarily to blame for these problems.

During the morning [7:00 AM to 11:00 AM], afternoon [11:00 AM to 4:00 PM], and evening [4:00 PM to 9:00 PM] hours of the day recordings of weighted noise levels were recorded at three-minute intervals and the highest noise level was reported. The sound level meter was installed at a $2.5 \mathrm{~m}$ and $5.0 \mathrm{~m}$ interval on both sides of the spots along the alignment, including the stoppage/signal position, and was installed at a height of $120 \mathrm{~cm}$ above ground level.

Traffic congestion assessment was done using Google Maps. This assessment was made from 7.00 AM to 9.00 PM and the observation interval was 15 minutes for the selected stoppage as like noise pollution measurement. Traffic congestion monitory report was recorded for every 15 minutes for the whole busy hour.

According to Google map, there are four types of assessment on traffic congestion and are green, orange, red, and dark red color line. The green color line means the traffic is moving freely on the streets. Based on the waiting time of vehicles in a traffic jam on a portion of the street monitored by satellite (GPS technology) it provides orange, red, and dark red marking on the street. Hence, the green line means no slowing vehicle and other signal indicates the vehicles are not able to run on its full velocity because of traffic congestion. This same procedure has been performed for seven consecutive days on a regular time to make an average assessment of a week neglecting any individual days' impact. After that, the time coverage portion under different color lines has been computed using excel programing and shown in table 3 for both direction traffic movement conditions of Natun Bazar to Farmgate route. Based on this data overall average access on this route for traffic movement has been computed as a simple average formula and exhibited in table 4. Besides this, we assessed the passenger (30 private cars, 30 motor vehicles, 30 local buses, and $30 \mathrm{CNG}$ ) how much time they required to travel this route and finally we made an average of time they experienced to travel this route and showed in table 5 .

Table 1. Ambient noise level standards in Bangladesh.

\begin{tabular}{llll}
\hline \multirow{2}{*}{ Category } & \multirow{2}{*}{ Zones } & \multicolumn{2}{l}{ Standard Value (dBa) } \\
\cline { 3 - 4 } & & Day & Night \\
\hline A & Quiet zones & 45 & 35 \\
B & Residential area & 50 & 40 \\
C & Mixed area & 60 & 50 \\
D & Commercial area & 70 & 60 \\
E & Industry area & 75 & 70 \\
\hline
\end{tabular}

\subsection{Noise Level Standards in Bangladesh}

Ambient noise level standards for different zones in Bangladesh approved by Bangladesh Environmental Conservation Act 1997 has been exhibited in table 1. [32]

\subsection{Noise Level Measurement Procedure}

The measurements have been duly monitored with the Sound Level Meter (Model: ST-8820) which continuously displays the Sound Pressure Level (SPL), Equivalent Sound Level, Maximum and Minimum Sound Pressure Levels, and Sound Exposure Level (SEL) over the specified operating time. The appropriate A-weighted sound-pressure-level data were recorded during the morning [7:00 AM to 11:00 AM], afternoon [11:00 AM to 4:00 PM], and evening [4:00 PM to 
9:00 PM] hours of the day. Recordings of weighted noise levels were recorded at three-minute intervals and the highest noise level was reported. The sound level meter was installed at a $2.5 \mathrm{~m}$ and $5.0 \mathrm{~m}$ interval on both sides of the spots along the alignment, including the stoppage/signal position, and was installed at a height of $120 \mathrm{~cm}$ above ground level. This measurement was taken for seven days continuously and made an average noise level for seven days on the selected spot and the final report has been exhibited in table 2 .

Table 2. Noise level intensity in different location [Natun Bazar to Farmgate route].

\begin{tabular}{|c|c|c|c|c|c|c|c|c|}
\hline Date Location & $06 / 07 / 2020$ & 07/07/2020 & 08/07/2020 & $09 / 07 / 2020$ & $10 / 07 / 2020$ & $11 / 07 / 2020$ & $12 / 07 / 2020$ & Avg. \\
\hline Natun Bazar & 92.3 & 95.0 & 94.6 & 92.0 & 95.5 & 93.8 & 92.2 & 93.6 \\
\hline Gulshan-2 & 100.9 & 100.8 & 101.8 & 102.2 & 102.9 & 102.2 & 103.1 & 102.0 \\
\hline Banani & 105.4 & 108.7 & 105.0 & 107.9 & 107.1 & 104.9 & 105.3 & 106.3 \\
\hline Shoinik Clab Mor & 100.9 & 99.7 & 100.7 & 103.9 & 103.1 & 103.8 & 104.1 & 102.3 \\
\hline Mohakhali Fly-over & 99.9 & 100.9 & 101.9 & 102.1 & 102.5 & 102.1 & 102.9 & 101.8 \\
\hline Jahangir Gate & 101.9 & 101.8 & 100.8 & 101.9 & 100.7 & 104.1 & 99.1 & 101.5 \\
\hline Bijoy Sarani & 99.1 & 101.9 & 102.8 & 99.1 & 100.8 & 105.1 & 99.9 & 101.2 \\
\hline
\end{tabular}

Table 3. Average traffic accessibily from Natun Bazar to Farmgate route based on traffic signal.

\begin{tabular}{|c|c|c|c|c|c|c|c|c|c|}
\hline Route direction & Signal & Natun Bazar & Gulshan-2 & Banani & Shoinik Clab Mor & Mohakhali Fly-over & Jahangir Gate & Bijoy Sarani & Farmgate \\
\hline \multirow{4}{*}{$\begin{array}{l}\text { Natun Bazar to } \\
\text { Farmgate }\end{array}$} & $\mathrm{G}$ & 63.41 & 8.52 & 3.76 & 5.26 & 29.07 & 4.51 & 5.76 & 8.77 \\
\hline & $\mathrm{O}$ & 27.50 & 38.85 & 35.34 & 35.29 & 40.10 & 30.82 & 30.33 & 21.81 \\
\hline & $\mathrm{R}$ & 8.09 & 42.61 & 49.87 & 46.13 & 26.57 & 45.87 & 44.86 & 42.59 \\
\hline & M & 1.00 & 10.02 & 11.03 & 13.32 & 4.26 & 18.80 & 19.05 & 26.83 \\
\hline \multirow{3}{*}{$\begin{array}{l}\text { Farmgate to } \\
\text { Natun Bazar }\end{array}$} & $\mathrm{G}$ & 59.21 & 10.78 & 6.02 & 7.27 & 31.33 & 6.52 & 9.03 & 9.28 \\
\hline & $\mathrm{O}$ & 36.34 & 38.60 & 38.01 & 39.86 & 37.60 & 31.08 & 30.08 & 22.81 \\
\hline & $\mathrm{R}$ & 3.80 & 42.11 & 42.8 & 42.36 & 26.32 & 45.87 & 43.36 & 38.83 \\
\hline
\end{tabular}

\section{Results and Discussion}

The intensity of people to press hydraulic horn has a clear relation with the signal provided by traffic police at the different locations all over the study region which is clear from figures 2-4. Natun Bazar to Farmgate is a two-way road and traffic moves in both ways. For this reason, the study of vehicle accessibility has been studied both ways. During this study report, it is clear that people waiting up to a certain level tend to press the hydraulic horn to make a concern of the traffic police to provide their route as free access for the vehicles. But if the waiting time limit is for a longer period they lose interest in pressing the horn as the traffic police have not seemed to be altered his mind to provide free access. On the other hand, it is blatant that if the traffic signal is always green then most of the drivers don't interest to press the horn in vain. Most of the driver's press horns just to make a reminder to slower vehicles ahead to provide trafficfree access so that they might overtake the vehicle during the green signal time. Natun Bazar has the lowest noise polluted $(93.6 \mathrm{dBa})$ area compared to other spots that have been studied in this research work and it is clear from figures 2-4 that is the benefit of highest free accessibility $(63.41 \%)$ of the vehicle in this link road and well planning about traffic movement. The effects of individuals' driver attitudes have been documented based on questionnaire surveys and field observation. It is noticeable that they are experiencing significant issues such as headaches, decreased job performance, decreased focus, exhaustion, tension, and tiredness.
Google map has become popular all over the world for its numerous features added day by day. People can check their destination route condition before starting their travel. Using Google Maps apps, we made a study of present traffic accessibility on the Natun Bazar to Farmgate route. We have found that although this whole route is 4 lane road considering the present scenario most of the portion of this route was found accompanied by overloaded mixed traffic. There is no consideration or strict rules that have been followed for this mixed traffic and erratic movement of the vehicle in the roadway. It is also explored that the more the arterial roads connected with the main roads the more the traffic jam occurred and these spot works as a source of noise pollution to attract the concentration of traffic police. A total of 6 arterial roads connected in Farmgate area and that's why most of the time of a day there is a huge wastage of time occur for only traffic jam and there is a negative impact in the national economy as this route is very important for the economic zone. For Natun Bazar to Farmgate route only $8.77 \%$ and for Farmgate to Natun Bazar route only $9.28 \%$ of a day there is free accessibility of traffic movement which is so poor a developing country like as Bangladesh. 21.81\%, $42.59 \%$ \& $26.31 \%$ of a day the driver gets the yellow line, red line, and dark red line coverage from Natun Bazar to Farmgate route and $22.81 \%, 38.83 \% \& 29.08 \%$ of a day the propeller finds the yellow line, red line and dark red line coverage from Farmgate to Natun Bazar route [Table 3]. On an average of $9.06 \%$ and $8.46 \%$ of a day the propeller gets free access on this route based on the traffic movement direction [Table 4]. This research was carried out from 7:00 AM to 9:00 PM [14 hours] for several consecutive days. So, from this analysis, we can say that during this 14 hours' busy 
time 1 hour and 16 minutes [9.06\%] or 1 hour and 11 minutes $[8.46 \%]$ the passenger can travel freely and rest of the time they have to spend in vain which is a huge loss for any developing country.

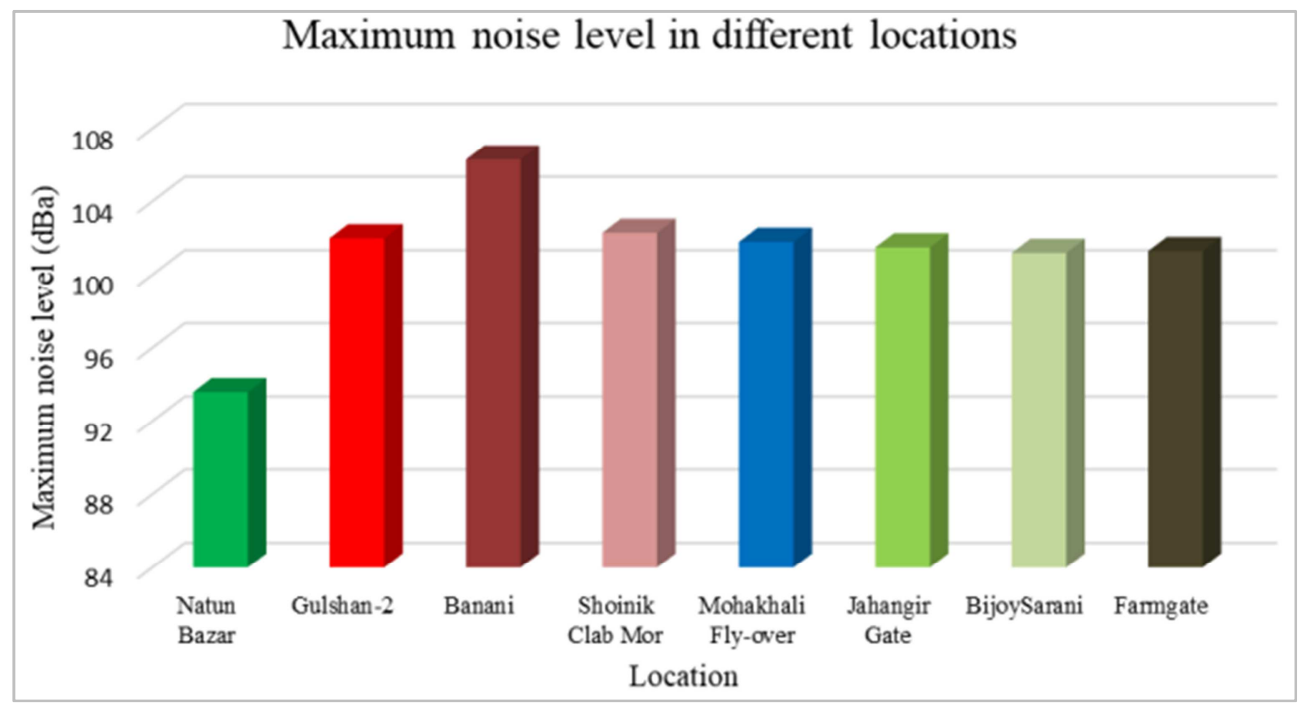

Figure 2. Maximum noise level in different locations.

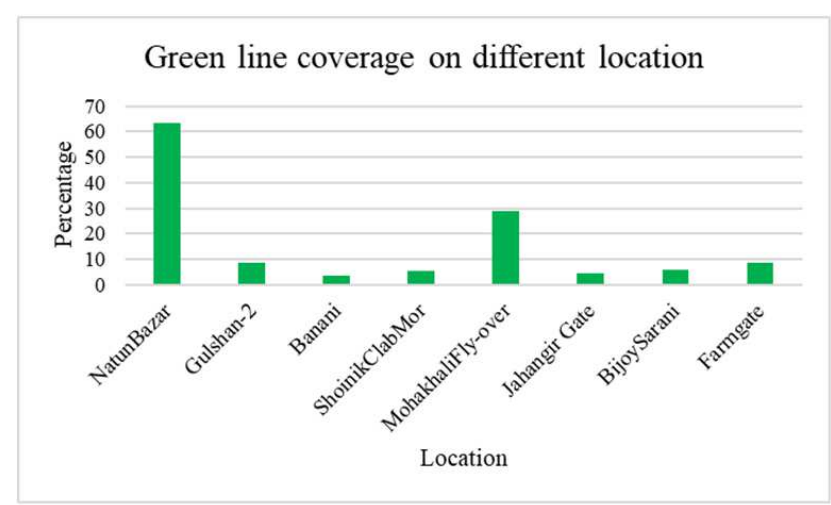

(a) Green line

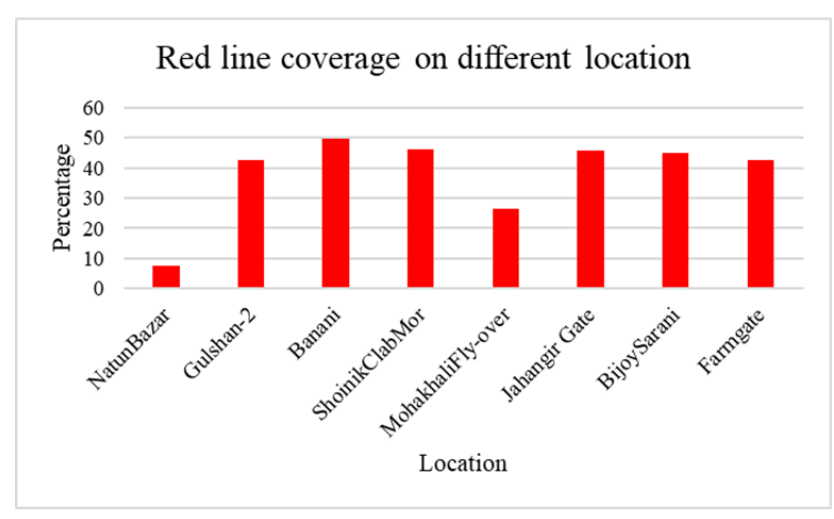

(c) Red line

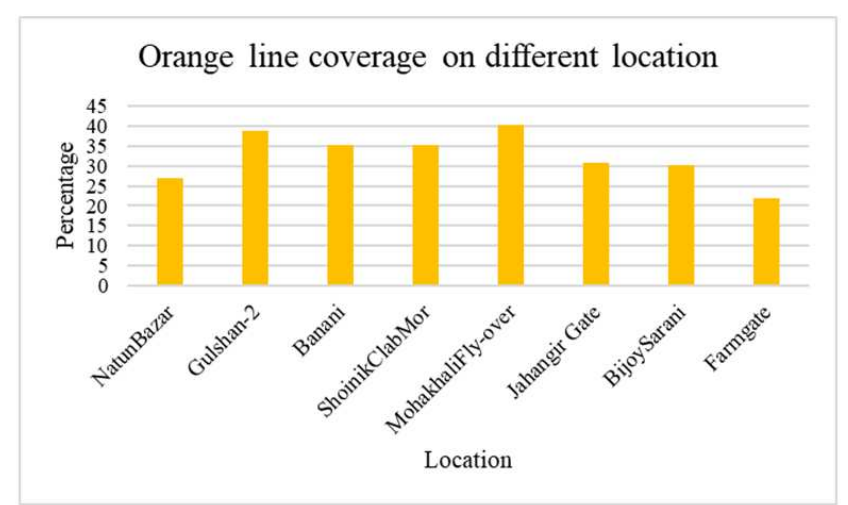

(b) Orange line

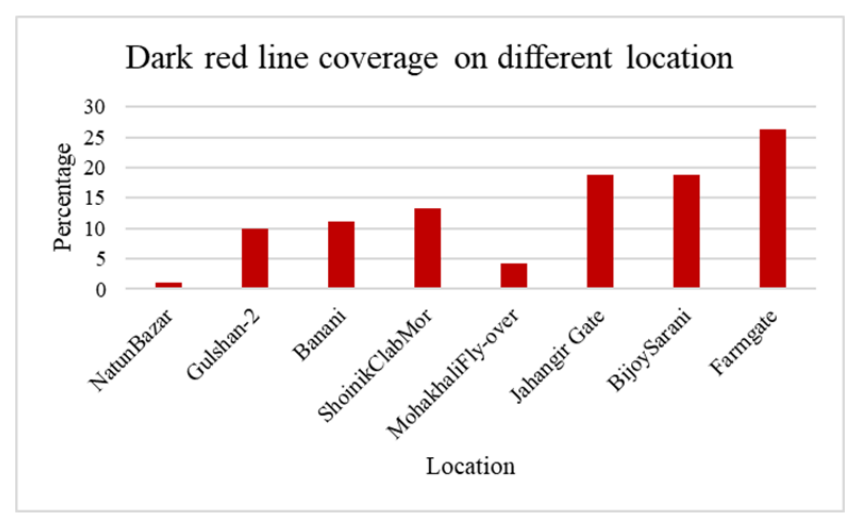

(d) Dark Red line

Figure 3. Vehicle accessibility for different line coverage from Natun Bazar to Farmgate route direction. 


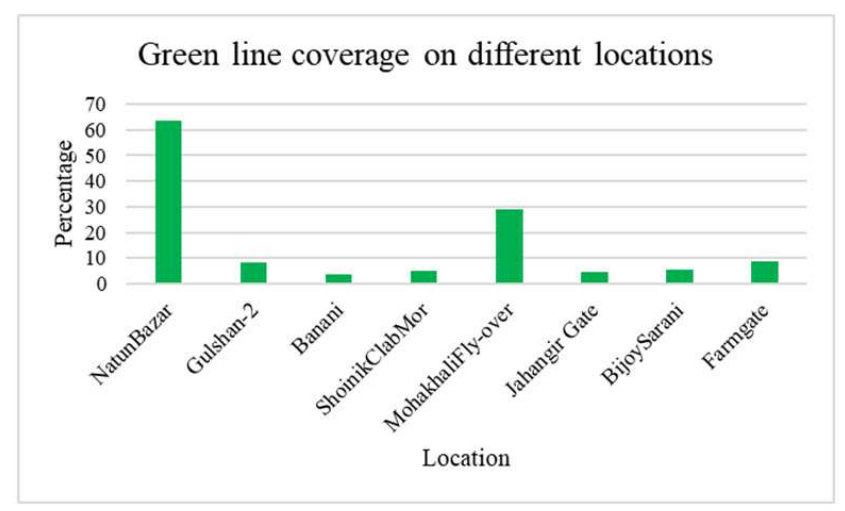

(a) Maximum noise level in different locations.

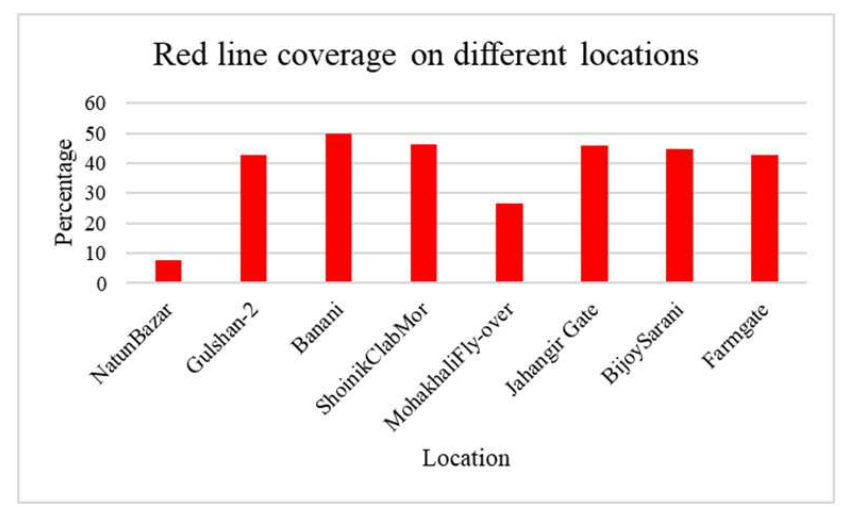

(c) Maximum noise level in different locations.

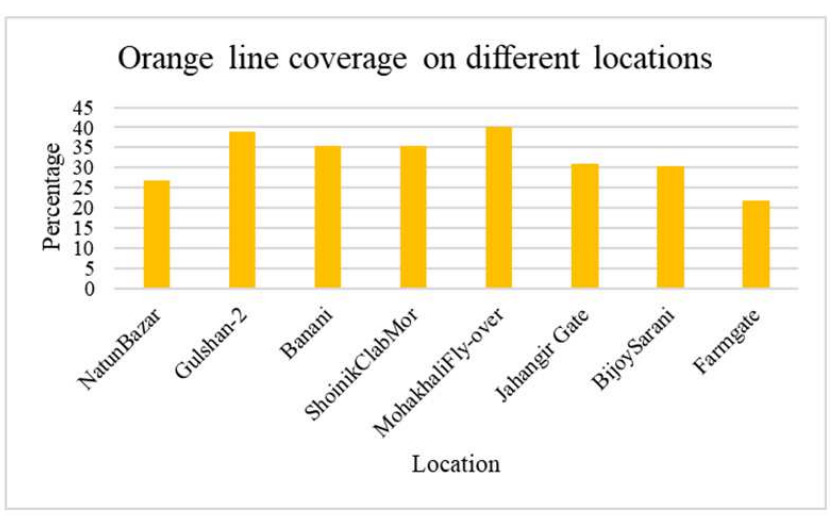

(b) Maximum noise level in different locations.

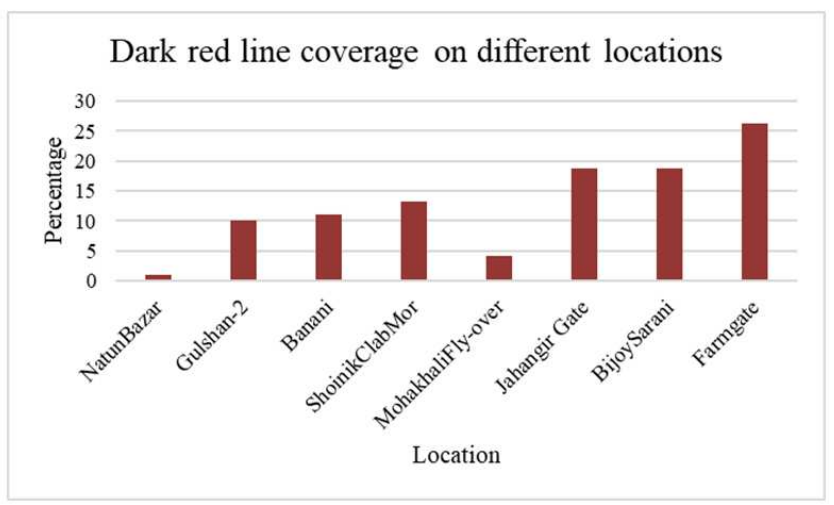

(d) Maximum noise level in different locations.

Figure 4. Vehicle accessibility for different line coverage from Natun Bazar to Farmgate route direction.

Table 4. Overall accessibility percentage of the road.

\begin{tabular}{lll}
\hline Route direction & Signal & Overall road coverage percentage (\%) \\
\hline & $\mathrm{G}$ & 9.06 \\
Natun Bazar to & $\mathrm{O}$ & 5.73 \\
Farmgate & $\mathrm{R}$ & 7.12 \\
& $\mathrm{M}$ & 78.09 \\
& $\mathrm{G}$ & 8.46 \\
Farmgate to & $\mathrm{O}$ & 5.69 \\
Natun Bazar & $\mathrm{R}$ & 6.55 \\
& $\mathrm{M}$ & 79.3 \\
\hline
\end{tabular}

This route is $7 \mathrm{~km}$ in length only but takes a long time to travel mainly due to improper planning of the city. An average of around 2 hours is required to cross this whole road [Table 5]. Motor vehicle and the private car is a high-speed vehicle with privet ownership and hence they mainly try to travel their destination within shortest possible time. But on the other hand, CNG drivers and bus drivers waste time mainly for searching purposes. That's why they are responsible for the delay.

Table 5. Average travel time from Natun Bazar to Farmgate route.

\begin{tabular}{ll}
\hline Type of Vehicle & Average travel time (hr.) \\
Bus & 3.25 \\
Car & 1.25 \\
Motor Vehicle & 1.10 \\
CNG & 2.50 \\
\hline
\end{tabular}

In the last decade neither the road width has been increased nor new strategies have been adapted in the roadway, Bangladesh Road Transport Corporation [BRTC] has permitted 1558 buses and 500 trucks to run in Dhaka city. During the last six years' city, bus routes have been doubled and these buses are more responsible for traffic jam because they pick up traffic from anywhere in the route as well as they wait for searching passenger blocking the passage for traffic. The total number of vehicles in Dhaka city is currently 1,517,929. Among these 35,834 buses, 10,721 minibuses, 21,498 auto-rickshaws, 708,970 motorcycles, and 291,082 automobiles are available. [33] As a result, the average velocity of Dhaka city has decreased to $4.5 \mathrm{~km}$ from $21 \mathrm{kmph}$ over the last twelve years. [34] Where it was required 20 minutes to travel such length of the road, now required 1 hour 33 minutes considering the average velocity of Dhaka city. But practically it requires 2 to 3 hours as the average velocity of the vehicle on this road is the lowest among this capital city, Dhaka. Every day, Dhaka's traffic costs the nation 3.2 million hours of work. [35] This time killing road will continue a bad impact on the national economy if it continues.

Natun Bazar to Farmgate is one of the major roads of the country as well the economy of Bangladesh will greatly depend on the future traffic condition of the capital city, Dhaka. Although there are some major projects is running to mitigate this present scenario but it has made it too late to perform. More planning work is necessary before the end of 
the life cycle of a road about the possible alternative ways for passenger transport system by minimum installment on the present roadway.

\section{Conclusions}

From the above study, we can conclude the followings:

a. Considering Natun Bazar to Farmgate route maximum percentage of green signal coverage was $63.41 \%$ in Natun Bazar and the maximum percentage of Dark Red signal coverage was $26.31 \%$ in Farmgate on an average of seven study days' period.

b. On the other hand, when the route was Farmgate to Natun Bazar we have found the maximum percentage of Green Signal coverage was 59.21\% in Natun Bazar and the maximum percentage of Dark red signal coverage was $29.97 \%$ in Farmgate on an average of seven study days' period.

c. We have found maximum average noise level is 106.3 $(\mathrm{dBa})$ in Banani and the minimum noise level is 93.6 $(\mathrm{dBa})$ in Natun Bazar which is very alarming for the city dwellers.

d. This excessive noise level $(\mathrm{dBa})$ proves that the noise level in Dhaka city is unpleasant for the passenger as well as the laborers and people who work in the industry or live in the residence beside this route.

\section{Conflict of Interest}

On behalf of all authors, the corresponding author states that there is no conflict of interest.

\section{References}

[1] R. Shamsher and M. N. Abdullah, "Traffic Congestion in Bangladesh- Causes and Solutions: A study of Chittagong Metropolitan City," Asian Bus. Rev., vol. 2, no. 1, p. 13, 2015.

[2] R. Al Haq, "Road Transport Act 2018 - details, repercussions, reactions." [Online]. Available: https://www.thedailystar.net/shift/news/road-transport-act2018-details-repurcussions-reactions-1823818. [Accessed: 12Apr-2021].

[3] A. de Palma and R. Lindsey, "Traffic congestion pricing methodologies and technologies," Transp. Res. Part C Emerg. Technol., vol. 19, no. 6, pp. 1377-1399, 2011.

[4] I. Jacyna-Gołda, Z. Jolanta, and P. Gołêbiowski, "Models of traffic flow distribution for various scenarios of the development of proecological transport system," Arch. Transp., vol. 32, no. 4, pp. 17-28, 2014.

[5] M. Wasiak, M. Kłodawski, K. Lewczuk, R. Jachimowski, and E. Szczepański, "Chosen Aspects of Simulation Model To Designing Pro-Ecological Transport System," J. KONES. Powertrain Transp., vol. 21, no. 4, pp. 525-532, 2014.

[6] P. Galilea and J. de D. Ortúzar, "Valuing noise level reductions in a residential location context," Transp. Res. Part D Transp. Environ., vol. 10, no. 4, pp. 305-322, 2005.
[7] M. Jacyna, M. Wasiak, K. Lewczuk, and M. Kłodawski, "Simulation model of transport system of Poland as a tool for developing sustainable transport," Arch. Transp., vol. 31, no. 3, pp. 23-35, 2014.

[8] P. Vaitiekūnas and R. Banaityte, "Modeling of motor transport exhaust pollutant dispersion," J. Environ. Eng. Landsc. Manag., vol. 15, no. 1, pp. 39-46, 2007.

[9] M. Jacyna et al., "the Influence of Road Transport on Emission of Toxic Substances in Poland Against the Eu Countries," J. KONES. Powertrain Transp., vol. 21, no. 3, pp. 133-140, 2014.

[10] D. Pal and D. Bhattacharya, "Effect of road traffic noise pollution on human work efficiency in government offices, private organizations, and commercial business centres in Agartala City using fuzzy expert system: A case study," $A d v$. Fuzzy Syst., vol. 2012, 2012.

[11] E. Öhrström and A. Skånberg, "Sleep disturbances from road traffic and ventilation noise-laboratory and field experiments," J. Sound Vib., vol. 271, no. 1-2, pp. 279-296, 2004.

[12] V. Singh, A. Prasad, Atul, and A. Imam, "Study of Effect of Traffic Noise on the Residensials of the Allahabad City," IOSR Joural Eng., vol. 8, no. 9, pp. 68-75, 2018.

[13] A. Korzhenevych et al., "Update of the Handbook on External Costs of Transport: final report for the European Commission DG MOVE," Ricardo-AEA, no. 1, p. 139, 2014.

[14] UNB, "Noise pollution: Will Dhaka ever be quiet?," Dhaka Tribune, Dhaka, 2021.

[15] L. C. (Eelco) den Boer and A. (Arno) Schroten, "Traffic noise reduction in Europe Health effects, social costs and," no. August, pp. 1-64, 2007.

[16] B. Jakovljevic, K. Paunovic, and G. Belojevic, "Road-traffic noise and factors influencing noise annoyance in an urban population," Environ. Int., vol. 35, no. 3, pp. 552-556, 2009.

[17] K. Fuks et al., "Long-term urban particulate air pollution, traffic noise, and arterial blood pressure," Environ. Health Perspect., vol. 119, no. 12, pp. 1706-1711, 2011.

[18] Q. LUO, Z. JUAN, B. SUN, and H. JIA, "Method Research on Measuring the External Costs of Urban Traffic Congestion," J. Transp. Syst. Eng. Inf. Technol., vol. 7, no. 5, pp. 9-12, 2007.

[19] D. Stokols, R. W. Novaco, J. Stokols, and J. Campbell, "Traffic congestion, Type A behavior, and stress.," J. Appl. Psychol., vol. 63, no. 4, pp. 467-480, 1978.

[20] M. M. Razzaque, S. C. Chowdhury, M. M. Helali, and H. Bodén, "On the impacts of noise pollution in Dhaka," 17th Int. Congr. Sound Vib. 2010, ICSV 2010, vol. 4, no. July, pp. 3068-3074, 2010.

[21] J. J. Mackenzie, R. C. Dower, and D. D. T. Chen, THE GOING RATE : What it Really Costs to Drive. 1992.

[22] H. Di et al., "Estimation of the quality of an urban acoustic environment based on traffic noise evaluation models," Appl. Acoust., vol. 141, no. July, pp. 115-124, 2018.

[23] S. Chakraborty, "Traffic Congestion in Dhaka City and its Economic Impact," Dhaka Univ. J. Bus. Stud., vol. 1, no. 2004, 2016. 
[24] D. Singh, S. P. Nigam, V. P. Agrawal, and M. Kumar, "Vehicular traffic noise prediction using soft computing approach," J. Environ. Manage., vol. 183, pp. 59-66, 2016.

[25] A. Mohan Rao and K. Ramachandra Rao, "Measuring Urban Traffic Congestion - a Review," Int. J. Traffic Transp. Eng., vol. 2, no. 4, pp. 286-305, 2012.

[26] "HIGHWAY TRAFFIC NOISE ANALYSIS AND ABATEMENT POLICY AND GUIDANCE," U.S. DEPARTMENT OF TRANSPORTATION, 1995. [Online]. Available:

https://www.nonoise.org/library/highway/policy.htm.

[Accessed: 10-Apr-2021].

[27] M. G. Mostafa, "Occupational Hazard of Brick Kiln Worker At High Intensity Occupational Hazard of Brick Kiln Worker At High Intensity," no. October, 2019.

[28] RSG, "Noise Measurement Handbook - Final Report. FHWAHEP-18-065," p. 205, 2018.

[29] U. S. A. Massachusetts, Handbook of Noise Measurement $t$, Nllfi lilt, 7th ed., no. 5301. General Radio, 1980.

[30] V. K. Patil and P. P. Nagrale, "Effective analysis of noise levels due to vehicular traffic in urban area using deep learning with OALO model," Int. J. Comput. Appl., vol. 0, no. 0 , pp. 1-10, 2020.
[31] A. M. Dewan and R. J. Corner, Dhaka megacity: Geospatial perspectives on urbanisation, environment and health. New York, NY, USA, 2014.

[32] D. Stage and D. P. Number, "Bangladesh : Bangladesh Power System Enhancement and Efficiency Improvement Project (Component 3 : Distribution System Upgrade, Rehabilitation, Extension, and Rural Electrification in BREB Service Areas Part 1) Dhaka, Mymensingh, Chittagong, a," vol. 1, no. September, 2016.

[33] S. Saif, "City bus routes more than double in 6 years," TBS News, 2020. [Online]. Available: https://www.tbsnews.net/bangladesh/road-transport/city-busroutes-more-double-6-years. [Accessed: 12-Apr-2021].

[34] S. Saif, "City speed drops to $4.5 \mathrm{kmph}$ from $21 \mathrm{kmph}$ in a decade," TBS News, 2020. [Online]. Available: https://www.tbsnews.net/bangladesh/2010s-look-backtransport-sector. [Accessed: 12-Apr-2021].

[35] D. BSS, "Traffic jam in Dhaka eats up $3.2 \mathrm{~m}$ working hrs everyday: WB," The Daily Star, 2017. [Online]. Available: https://www.thedailystar.net/city/dhaka-traffic-jamcongestion-eats-32-million-working-hours-everyday-worldbank-1435630. [Accessed: 12-Apr-2021]. 